\title{
PSYCHE
}

\begin{tabular}{lll}
\hline Vol. 94 & 1987 & No. 3-4 \\
\hline
\end{tabular}

\section{A MORDELLID-MELOID MIMICRY}

\author{
By M. DeYruP ${ }^{1}$ AND T. EISNER ${ }^{2}$
}

The Mordellidae are small wedge-shaped beetles commonly found in one of the most dangerous of all insect habitats, the open inflorescences of plants. Their chief protection against the many predators that frequent flowers is a series of convulsive leaps followed by rapid flight, as acknowledged in their common name, the "tumbling flower beetles" (Crowson, 1981). Their escape from a predator's grasp is facilitated by their wedge shape and covering of smooth, backward-pointing hairs, while their movement and purchase among stamens and floral hairs may be assisted by rows of tibial and tarsal setae strongly reminiscent of the combs of fleas. These escape mechanisms, while undoubtedly effective against many predators (including entomologists), have the disadvantage that they involve abandonment of the feeding site.

At our study area in southern Florida (Archbold Biological Station, Highlands Co.) one species of mordellid appears to belong to a mimetic complex, a strategy by which the beetles might forestall attack. The mordellid, Mordellistena comata LeConte, is a relatively uncommon insect that is found during late summer on flowers of yellow Asteraceae, especially Heterotheca subaxillaris (Lamarck) Britton and Rusby, and Balduinia angustifolia (Pursh) Robinson. The reddish pronotum and black elytra of this beetle (Fig. 1, bottom) confer a strong resemblance to several species of nemognathine meloids, especially Gnathium francilloni Kirby (Fig. 1,

\footnotetext{
'Archbold Biological Station, P.O. Box 2057, Lake Placid, Florida 33852.

${ }^{2}$ Section of Neurobiology and Behavior, Cornell University, Ithaca, New York 14853.

*Manuscript received by the editor July 6, 1987.
} 

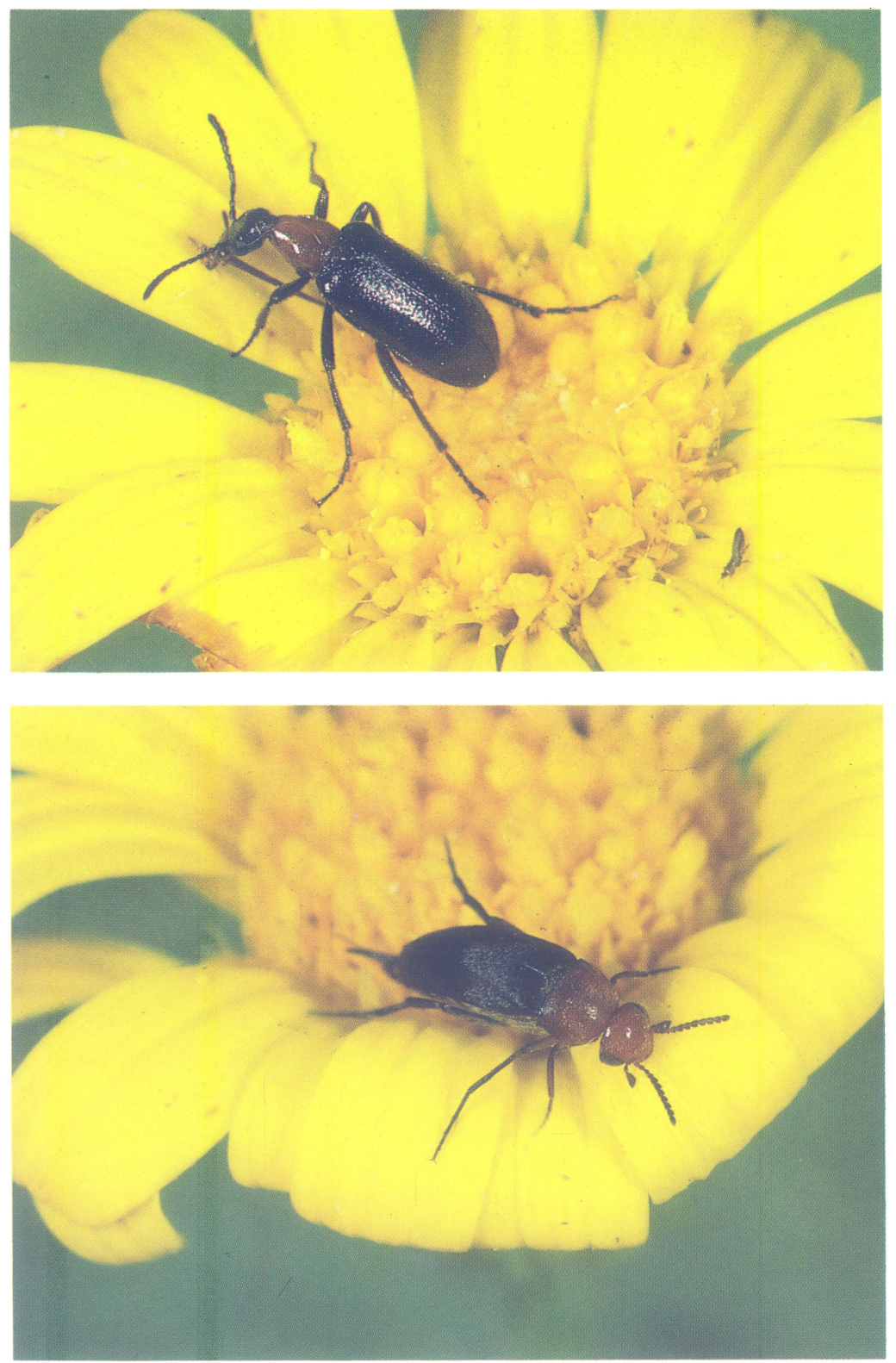

Fig. 1. The meloid Gnathium francilloni (above) and its mimic, the mordellid Mordellistena comata, on flowers of Heterotheca subaxillaris. Photographs taken at same magnification. Body length of Gnathium $=4.5 \mathrm{~mm}$. 
top). At one location in a dense stand of $\boldsymbol{H}$. subaxillaris covering an area of about $50 \times 50 \mathrm{~m}$, we counted 250 specimens of $G$. francilloni and 6 of M. comata. The meloids often occurred in groups of 2 or 3 (31 pairs were in copula), while the mordellids occurred singly. Visually, as small specks of reddish-brown and black on the brilliant yellow floral discs, the two species are difficult to distinguish. The differences apparent at very close range were not obvious to us at a distance. We had long been familiar with Gnathium at our field site before we noticed the Mordellistena among them.

Nemognathines can be expected to be protected chemically by cantharidin, the well-known terpenoid toxin present in meloid blood (Carrel and Eisner, 1974). Meloid beetles typically reflexbleed when disturbed, a behavior that we could readily induce in $G$. francilloni, as in other species of Gnathium, by gentle pinching of the body and legs. M. comata, we believe, may avoid harassment through mimicry of these protected models. Whether it is itself fully palatable and therefore (in a chemical sense) a Batesian mimic, remains unanswered. The literature offers no clue to the presence of chemical defensive agents in mordellids. Tests that we did with another species of mordellid, Mordella atrata (Melsheimer), proved this beetle to be edible: six individuals (freshly killed or rendered moribund by freezing) that we offered at our field site in a small dish to tame wild scrub jays (Aphelocoma c. coerulescens) were taken in quick succession by one bird, together with pieces of peanut offered as accompanying morsels. The same bird ate another 29 of $32 \mathrm{M}$. atrata that were similarly offered several days later, and a second bird ate two individuals of this lot, leaving only one of the beetles uneaten.

Examination of $G$. francilloni and $M$. comata by ultraviolet video-viewing (Eisner et al. 1969) showed no differences in ultraviolet reflectance characteristics. Both beetles are ultraviolet absorbent over their entire body surface. To the insect eye, therefore, the beetles should also appear similar in coloration.

$M$. comata and $G$. francilloni have more or less overlapping geographic ranges, according to the fragmentary data available (Blackwelder and Arnett, 1975). There are additional species of meloids, such as Nemognatha nemorensis Hentz, and one additional mordellid, Mordellistena marginalis Say, that occur on flowers and seem to belong to the red-pronotum, black-elytra mimetic complex. At the Archbold Biological Station this general complex includes about 90 species, belonging to various insect orders; most of these species 
cannot yet be assigned to specific mimetic associations of species found together in the same microhabitat.

The Mordellidae appear to be an ancient family of floricolous beetles (Crowson, 1981), and the scarcity of mimetic species might seem surprising. The small size of most species and their distinctive shape do not preadapt them for visual convergence with most of the stinging or distasteful species found on flowers. M. comata may be viewed as adaptively "fortunate" in co-occurring with a small, distasteful, floricolous species.

\section{ACKNOWLEDGMENT}

We thank Dr. Norville Downie, Lafayette, Indiana, for identifying the mordellids and meloids.

\section{Literature Cited}

Black welder, R. E., and R. H. Arnett, Jr.

1975. Checklist of the beetles of Canada, United States, Mexico, Central America, and the West Indies. Vol. 1, part 5. The darkling beetles, ladybird beetles and related groups. Biol. Res. Instit. of America, Rensselaerville, N.Y. (not paginated).

CARrel, J. E. AND T. EISNER

1974. Cantharidin: potent feeding deterrent to insects. Science 183: 755-757. Crowson, R. A.

1981. The biology of the Coleoptera. Academic Press, New York and London. $\mathrm{xii}+802 \mathrm{pp}$.

Eisner, T., R. E. Silberglied, D. Aneshansley, J. E. Carrel, and H. C. Howland.

1969. Ultraviolet video-viewing: the television camera as an insect eye. Science 166: 1172-1174. 

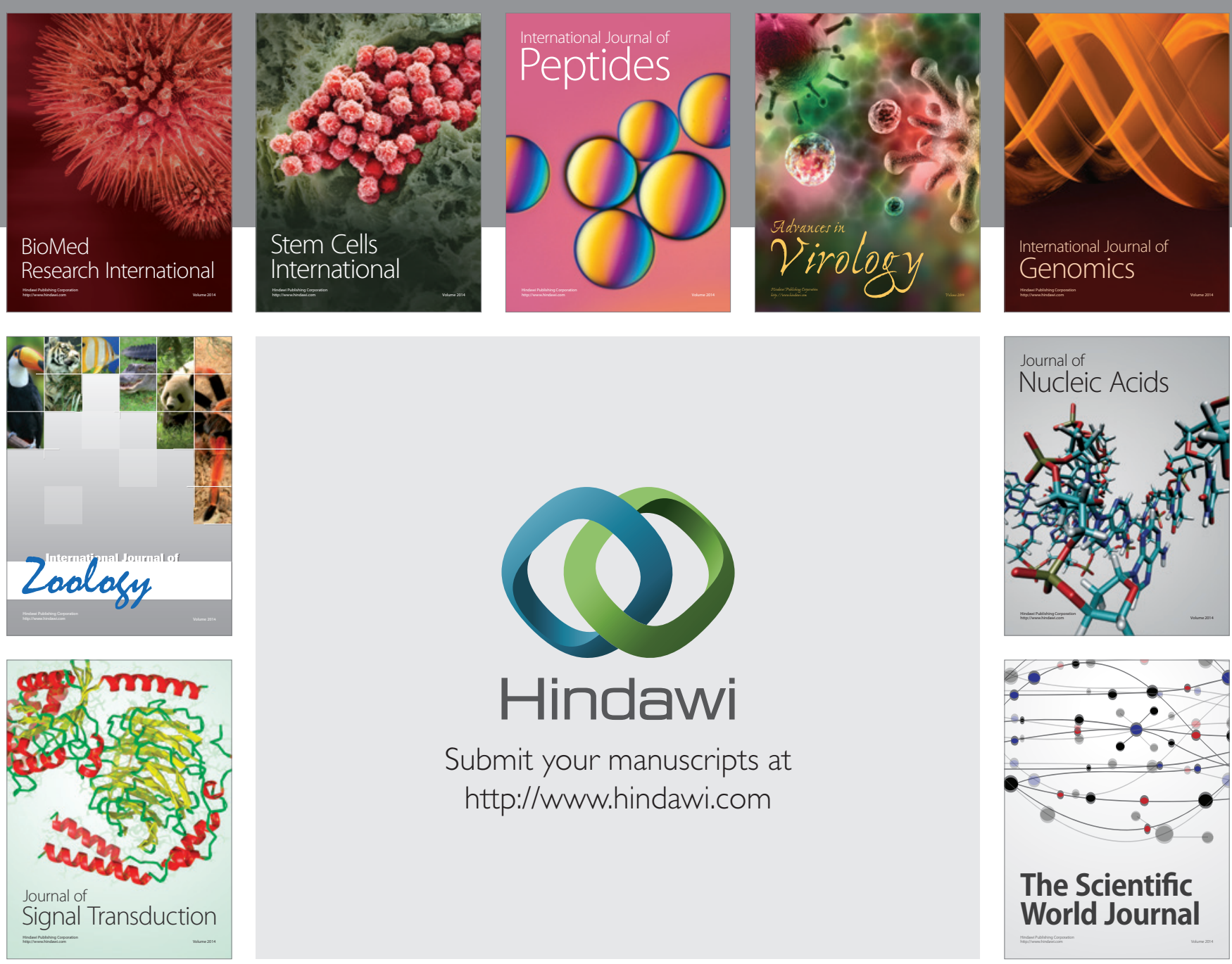

Submit your manuscripts at

http://www.hindawi.com
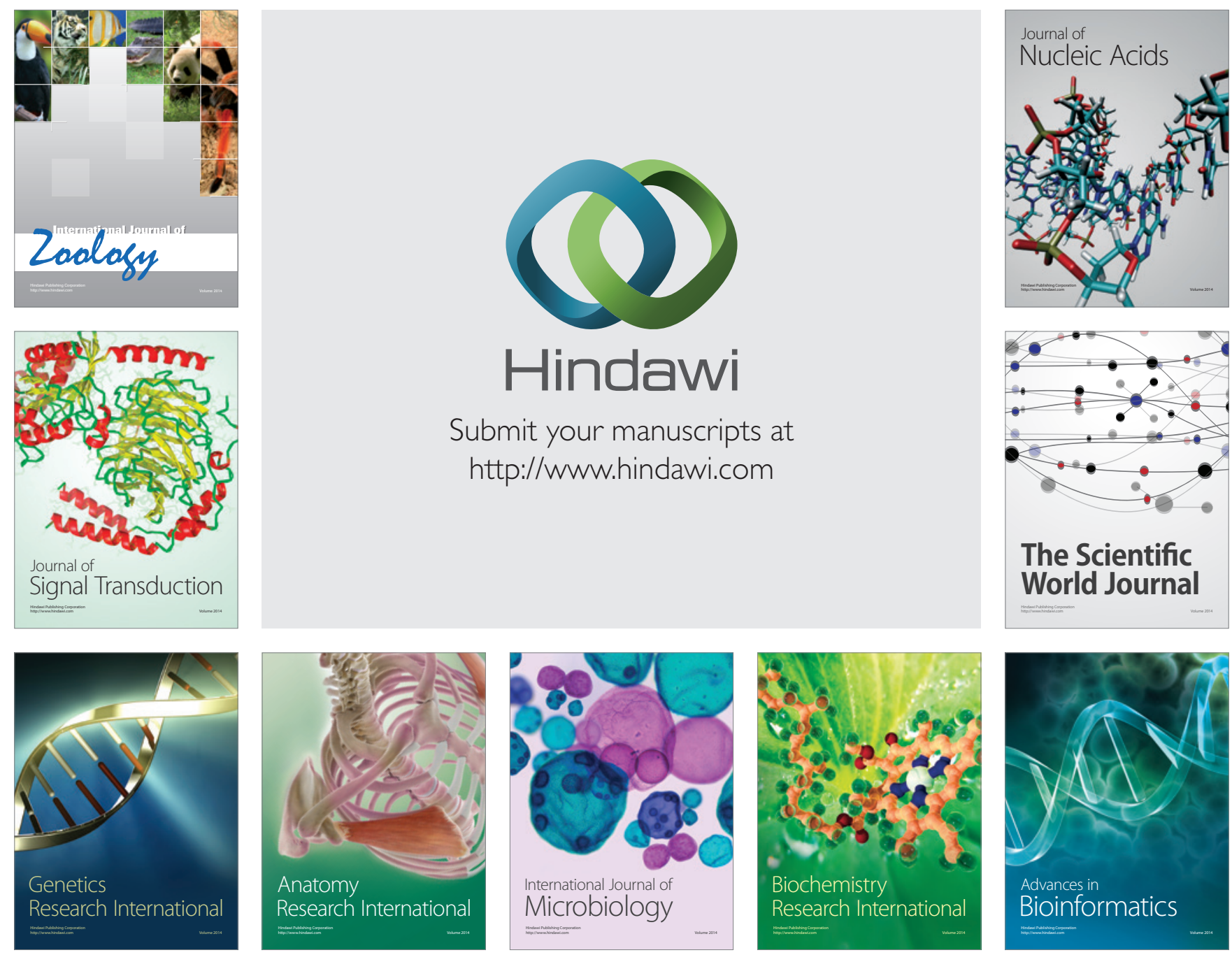

The Scientific World Journal
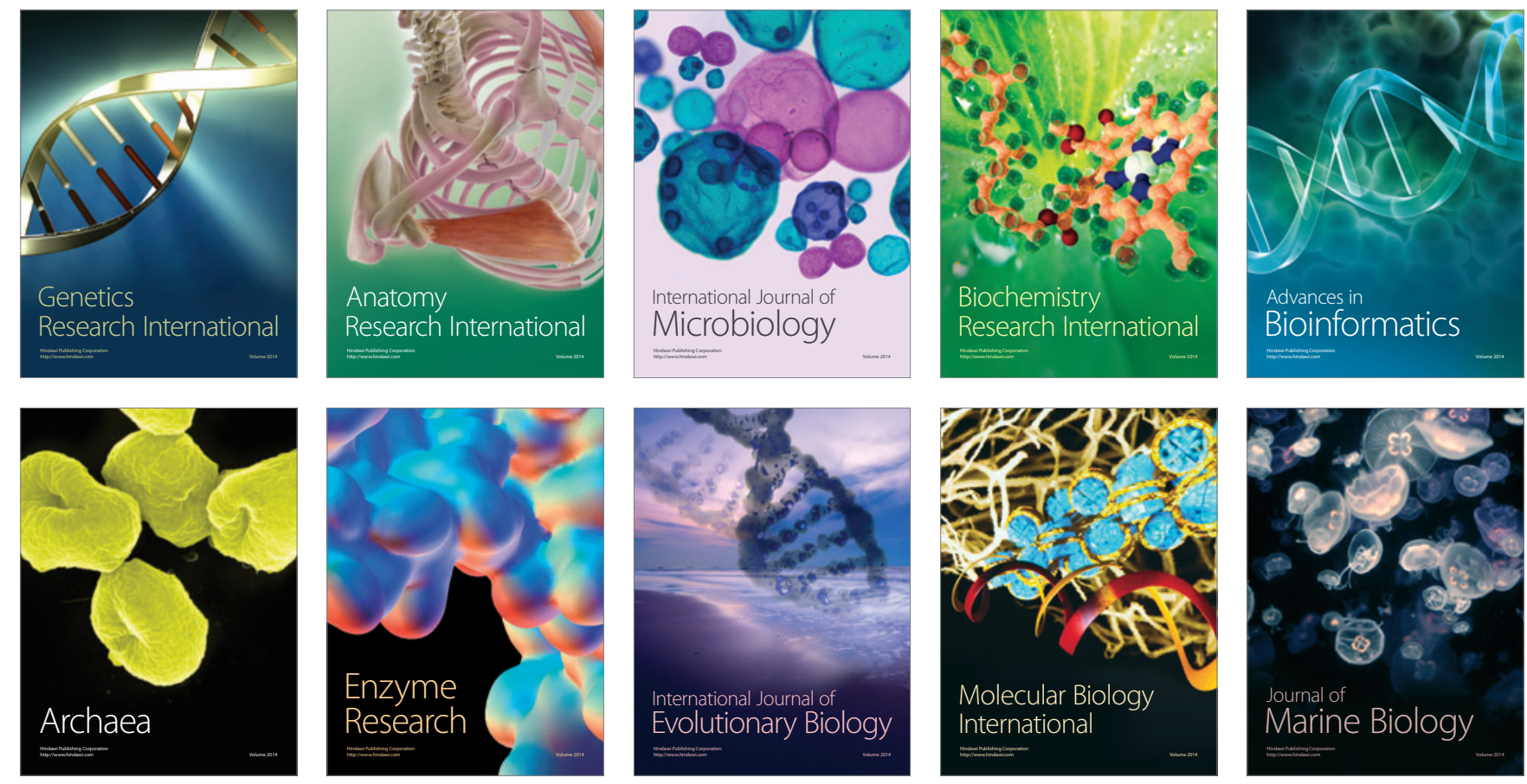